\title{
Editorial
}

\section{COVID-19 Thrombosis: An Unsolved Mystery}

\author{
Poonam Malhotra Kapoor ${ }^{1}$ \\ ${ }^{1}$ Department of Cardiac Anaesthesia, All India Institute of Medical \\ Sciences, New Delhi, India, Konya, Turkey \\ J Card Crit Care:2020;4:1-4
}

The COVID-19 pandemic, which has taken the world by surprise, is clearly, as evidenced last few months, procoagulation and thrombotic in etiology, as it is a collision of coagulation, inflammatory and complementary pathways. There are multiple reports and publications that this COVID-19 pandemic is associated with both arterial and venous thrombosis and pulmonary embolism, with marked increase in clots in extracorporeal circuits as well. ${ }^{1}$

\section{The Root of The Problem}

The novel Coronavirus (SARS-CoV-2) is a highly contagious disease, traveling from Hubei province of Wuhan, China, to the homes of millions globally, as it spreads as an airborne disease. It disrupts the endothelium in a positive patient, particularly of the lungs, where it infiltrates and consolidates gather. (-Figs. 1 and 2 ).

In patient autopsies done all over the world, ${ }^{2-5}$ there is evidence, on light microscopy, of clumps of inflammatory cells associated with the endothelium in the heart, lungs and small bowel, suggesting that this disease shows the presence of viral elements within endothelial cells, causing widespread vascular endothelial damage.

\section{Intensivists are Endothelioligists}

We as critical care intensivists are all endothelioligists, who need to fix the damaged endothelium back to its native form. As new treatment options show a promising rainbow in the near horizon, the darkened sky looks brighter. To quote a few sunny happenings in the SARS pandemic, the Health Ministry of India gave the go ahead on the use of the antiviral drug, remdesivir, in moderate stages of COVID-19. It has also cleared the air on the controversial antimalarial drug hydroxychloroquine, which according to the Indian Ministry guidelines, should be used in the early course of the disease and not in the critically ill patient. The advent of Moderna,
Oxford and serum institute of virology vaccine(s) has also, in recent times, cleared key hurdles, such as more virulence by the vaccine and the number of vaccine dosages required. While the data released by the US National institute of Allergy and Infectious Disease (NIAID) and Moderna offered some assurance on mice trials, the studies do not fully answer many questions. "This is the barest beginning of preliminary information," said Dr Gregory Poland, an immunologist; today, human trials of the vaccine are ongoing-a promise to a cure. ${ }^{6}$

\section{Lower Mortality in Indian Scenario}

Despite a massive increase in affected cases after unlocking, the reason for India's low-mortality rate, despite the number of infected crossing over 1 million, relates to the following: a timely lockdown, innate immunity, BCG vaccination at birth, and others, as has been summarized in - Fig. 3 .

The milder patients forming 80 to $85 \%$ of population get away with symptoms of fever, fatigue, dry cough, and loose motions. It is in the second and third week of the pandemic that an exponential increase in symptoms of lung infiltrate was observed. It is different from a typical acute respiratory distress syndrome (ARDS), more like pulmonary fibrosis, which worsens with thrombosis, renal failure, and a DIC (disseminated intravascular coagulation) type of presentation.

\section{What is the Evidence so Far? Covid Causes Immune- mediated Damage to the Hematopoietic System}

Patients immobilized with an active COVID-19 infection are immobile and experience prothrombotic changes. These changes also are seen in vessel walls and thus we see a hyperinflammation syndrome with elevated D-dimer and CD13 receptors getting activated.

The COVID-19 virus directly damages the megakaryocytes and platelets and expresses high-levels of CD13. They then invade the hematopoietic stem cells and infect the bone marrow, leading to thrombocytopenia.
Address for correspondence Poonam Malhotra Kapoor, MD, DNB, MNAMS, FTEE, FIACTA, FISCU, Department of Cardiac Anaesthesia, All India Institute of Medical Sciences, Ansari Nagar, New Delhi 110029, India (e-mail: drpoonamaiims@gmail.com).
DoI https://doi.org/ 10.1055/s-0040-1715279 ISSN 2457-0206.
(C)2020 Official Publication of

The Simulation Society (TSS), accredited by International Society of Cardiovascular Ultrasound (ISCU).
License terms

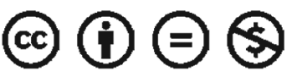




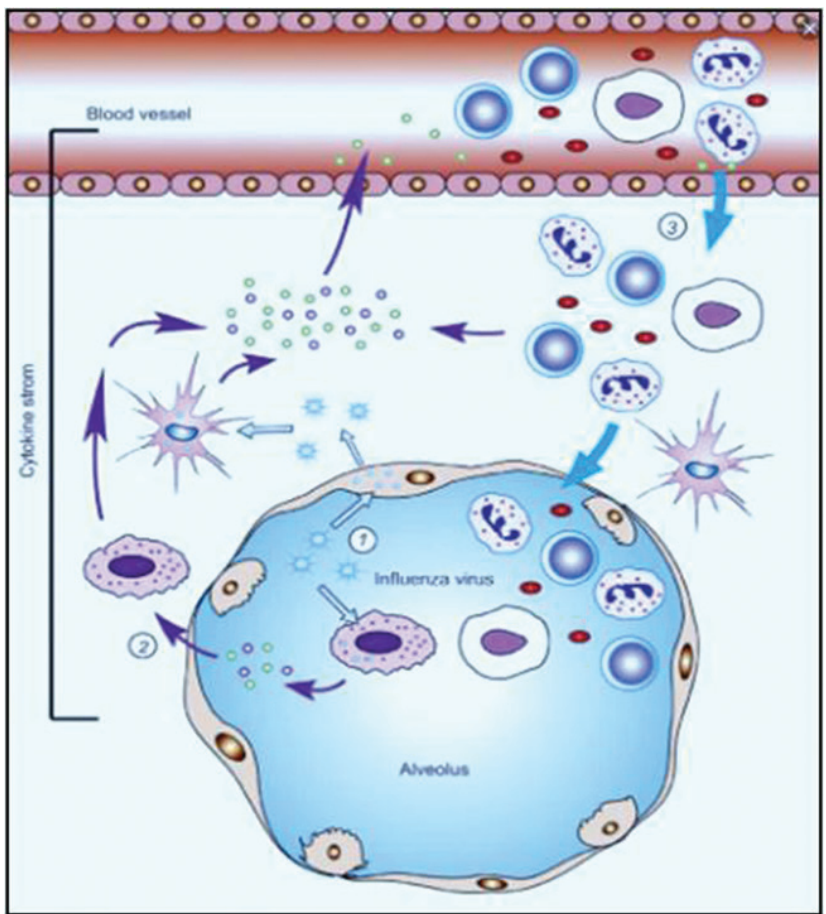

Fig. 1 Cytokine storm is the root of the problem.

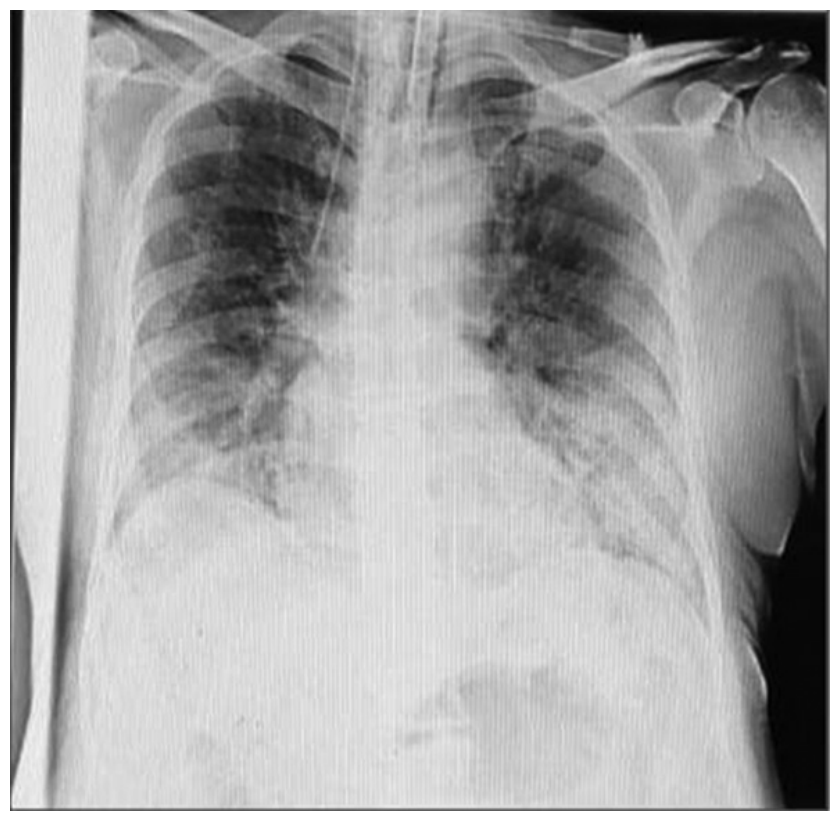

Fig. 2 X-ray of COVID-19 positive case.

\section{A Cytokine Storm Ensues}

The cytokine release syndrome ensues in the second week (day 11-15) and worsens with a rise in ILB13, IL6, IL12 IL10, and monocyte chemokine I (MCPI) over time. These inflammatory mediators upregulate the expression of vascular endothelial growth factor, particularly IL-6, which produces more thrombus and fibrinogen.

Endothelial cells express ACE2; thus, COVID-19 aggravates cell damage, upregulates tissue factor expression, and

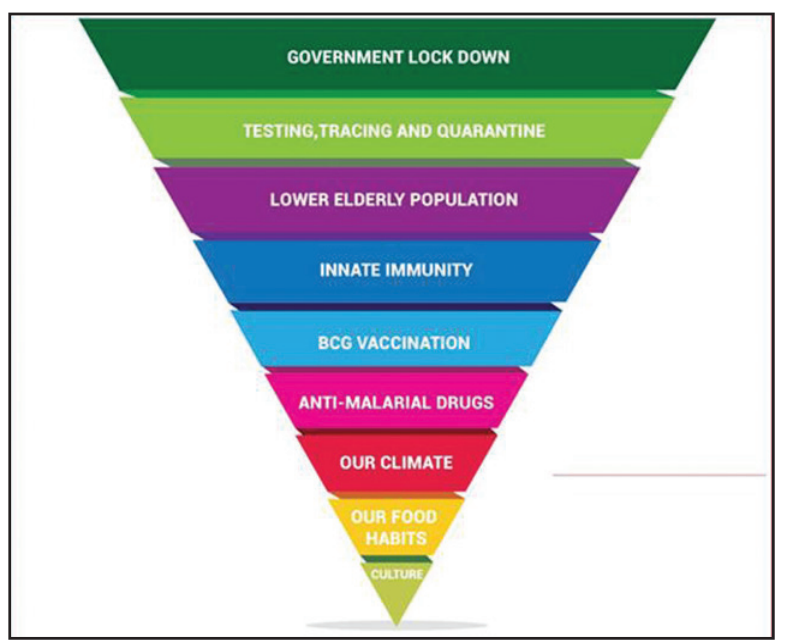

Fig. 3 Pyramid showing the possible reasons for low-death rate in India.

loosens antithrombin, TFPI (tissue factor pathway inhibitor) and protein C. This completely damages the endothelium and the anticoagulation system.

The virus attacks $\beta$ chain and dissociates heme, removing iron and converting it to porphyrin. The virus can dissociate oxyhaemoglobin, carboxyhaemoglobin, and glycosylated haemoglobin. This leads to lung inflammation due to inability of both oxygen and $\mathrm{CO}_{2}$ exchange, producing ground glass capacities on chest X-rays. Chloroquine completes the binding to porphyrin, and thus has been seen to be useful in Covid-19 prophylaxis (although controversial).

\section{Capturing the Cytokine Storm: Using Biomarkers in COVID-19 Trials}

SARS-CoV-2 studies show alterations in serum IL-2, IL-6, IL-7, granulocyte-colony stimulating factor, IP-10, MCP-1, MIP1- $\alpha$, and TNF- $\alpha$, which are positively correlated with COVID-19 disease severity. Therefore, larger multiplex panels measuring several markers together are recommended for speed, especially those that are well-characterized for reliability (e.g., Meso Scale Discovery (MSD) V-Plex Assays). ${ }^{7}$

The suppression of the "cytokine storm" is very essential in the ICU settings of these critically ill patients.

\section{What Does Most Recent Treatment Literature Tell Us?}

Clinical trials are underway to treat this "cytokine storm" with a plethora of anti-inflammatory drugs such as HCQ prednisolone, antiviral remdesivir, etc. but with caution, as no definitive treatment has been declared as yet by the WHO. Resting at home and social distancing is the best treatment, as it enables a small army of their own cells to attack the virus, thus preventing viral replication and helping to develop antibodies that prevent it from infecting new cells. These antibodies also provide some protection against reinfection by this COVID-19 virus at a later time. This storm theory could explain the crash that happens in the second week. 
Favipiravir binds to the virus envelope protein with very high affinity, prevents entry into the cells as well as binding of structural protein to porphyrin.

The marked elevation of IL- 6 in patients with cytokine release syndrome (CRS) led to the institution of successful targeted therapy for the treatment of CRS using IL-6 receptor blockade (tocilizumab). ${ }^{8}$ Measuring IL-6, however, involves a research tool not rapidly available as a CLIA-approved test in most centers. Therefore, the Sloan Kettering group's observation that levels of C-reactive protein (CRP), for which there is a rapidly available test, correlated with CRS severity, was a valuable contribution that has since been widely adopted. ${ }^{9}$

One important question still to be evaluated is whether earlier intervention with tocilizumab might reduce the morbidity and mortality from CRS without jeopardizing the impressive clinical responses of CD19 CAR-modified T cells. Future research will answer this query soon.

\section{COVID-19 and ECMO: the Interplay between Coagulation and Inflammation}

It is widely acknowledged that the majority of COVID-19 patients, especially those with severe disease, are characterized by lymphocytopenia. This laboratory symptom is observed mostly in adult patients and much less often in children. Notably, the currently available data strongly indicates that lymphocytopenia is dynamically modulated by the intensification of local and systemic inflammation, direct infection of lymphocytes, and destruction of lymphoid organs. In addition, treatment with glucocorticosteroids may cause lymphocytopenia in some cases. ${ }^{10}$

Support with extracorporeal membrane oxygenation (ECMO) is further not available in many low- and middle-income countries; therefore, ECMO might not seem to gain as much of a priority as personal protective equipment, correct management, diagnosis and quarantine, oxygen therapy alone, and mechanical ventilation in the first instance.

An ECMO therapy and COVID-19 itself are associated with certain, often synergistic changes in hematological and inflammatory status of the patients; the efficacy of ECMO is largely dependent on centers' experience with such therapies.

Where extracorporeal life support (ECLS) expertise is available, it should be considered according to the standard management algorithm for ARDS in supporting patients with viral lower respiratory tract infection. ${ }^{11}$ The venovenous ECMO, begun timely, is the right mode of ECMO, with facility for ECCO2 removal as well. Patients on left ventricular assist device (LVAD) support are particularly vulnerable to infectious complications due to the inherent presence of hardware and driveline exposure as well as the fact that prolonged support has been associated with immune dysregulation.

\section{Prone Position: is it Beneficial?}

Finally, prone ventilation is beneficial in cases of severe ARDS. The maneuver has been effective in improving lung mechanics and gas exchanges, and in some cases, it may prevent the need to escalate to venovenous extracorporeal membrane oxygenation. Although there are no published outcomes, early experience in Wuhan, China, indicates that prone position was widely used in patients with COVID-19 related severe ARDS and had possible benefits. ${ }^{12}$ Nonetheless, it may be prohibitive in heart failure patients on LVAD or ECMO support. Prone positioning could result in complications such as compression of outflow graft and driveline, impaired venous return from increased thoracic pressure, hardware malpositioning, and worsening right ventricular (RV) hemodynamics.

\section{COVID-19 Special Issue}

The rainbow in a clear sky for the COVID thrombosis is the 2020 issue of JCCC, where there are articles by our coagulation experts, Prof Klaus Gorlinger from Germany along with Dr. Ajay Gandhi, who elucidate the process of connecting the dots of COVID-19 coagulopathy. How to prepare a COVID ICU, and the right way to donning and doffing is brought in vivid articles by team of Dr. Kanchi Muralidhar and Jose Chacko from Narayana Hrudayalaya, Bangalore. The bright team from Medanta narrates the management of COVID-19 in the ICU. Direct news and feelings from the Italian epicenter by Dr. Fabiola Sozzi is worth a read as is the article on "COVID ECMO myths" along with our regular features-so read on and enjoy the fruits of the dedicated hard work of our authors.

In these uncertain times of the Coronavirus, where we all are learning to live differently, self-reliance of one's own creativity and hard work is all that we have, which will prove to be a winning streak. This war will be won with perseverance, patience and resilience.

Teachings from the "Bhagvat Gita" help us find solace as we face adversity in life in these times of Corona. It helps us reminiscence that "we are not the doers but mere seers" and that all changes remain with the Almighty." Let us continue to persevere as Mother Nature innately teaches us.

\section{Conflicts of Interest}

None declared.

\section{References}

1 Huang C, Wang Y, Li X, et al. Clinical features of patients infected with 2019 novel coronavirus in Wuhan, China. Lancet 2020;395(10223):497-506

2 Chen N, Zhou M, Dong X, et al. Epidemiological and clinical characteristics of 99 cases of 2019 novel coronavirus pneumonia in Wuhan, China: a descriptive study. Lancet 2020;395(10223):507-513

3 Darzi AJ, Karam SG, Charide R, et al. Prognostic factors for VTE and bleeding in hospitalized medical patients: a systematic review and meta-analysis. Blood 2020;135(20):1788-1810

4 Spyropoulos AC, Lipardi C, Xu J, et al. Modified IMPROVE VTE risk score and elevated D-Dimer identify a high venous thromboembolism risk in acutely ill medical population for extended thromboprophylaxis. TH Open 2020;4(1):e59-e65

5 Helms J, Tacquard C, Severac F, et al; CRICS TRIGGERSEP Group (Clinical Research in Intensive Care and Sepsis Trial Group for Global Evaluation and Research in Sepsis). High risk of 
thrombosis in patients with severe SARS-CoV-2 infection: a multicenter prospective cohort study. Intensive Care Med 2020;46(6):1089-1098

6 Poland G. JAMA coronavirus (COVID-19) update - vaccines and immunity. JAMA JN Learning 2020 . Available at: https:// edhub.ama-assn.org/jn-learning/video-player/18350099. Accessed July 6, 2020

7 Mehta P, McAuley DF, Brown M, Sanchez E, Tattersall RS, Manson JJ; HLH Across Speciality Collaboration, UK. COVID19: consider cytokine storm syndromes and immunosuppression. Lancet 2020;395(10229) :1033-1034

8 Lee DW, Gardner R, Porter DL, et al. Current concepts in the diagnosis and management of cytokine release syndrome. Blood 2014;124(2):188-195
9 Davila ML, Riviere I, Wang X, et al. Efficacy and toxicity management of 19-28z CAR T cell therapy in B cell acute lymphoblastic leukemia. Sci Transl Med 2014;6(224):224ra25

10 Sharma A, Sharan S, Kapoor PM, Chowdhury UK. COVID-19 ECMO myths busted. Journal of Cardiac Critical Care TSS (epub ahead of print). doi: 10.1055/s-0040-1713490

11 CDC. United States Center for Disease Control interim guidance for clinical management of COVID-19 patients with and without acute respiratory distress syndrome. Available at: https://www.cdc.gov/coronavirus/2019-ncov/hcp/clinicalguidance-management-patients.html. Accessed May 2, 2020

12 Meng L, Qiu H, Wan L. Intubation and ventilation amid the COVID-19 outbreak: Wuhan's experience. Anesthesiology 2020 (e-pub ahead of print. doi: https://doi.org/10.1097/ ALN.0000000000003296/unknown 